\title{
Addiction Enabling Doctors-- So You Want To Stop The Heroin And Drug Abuse Epidemic?
}

\author{
Volume 4 Issue 3 - 2015
}

\section{Opinion}

PLEASE PUBLISH AND PROMULGATE and maybe some real Opinion prevention of drug abuse will occur.

"Doctors Enabling Addiction" by Richard A. Friedman, NYTimes, 11-8-15 and "Time to renew the fight against the heroin epidemic" by Liam Garvin, Cleveland Plain Dealer 11-8-15 offer feeble steps in the right direction. The irrefragable are prompted:

1. First, the government should get out of the "practicing medicine" business. The Law of Unforeseen Consequences always rears its ugly head. Giving semi-monopoly of medicines to any subspecialty only results in calculated (and invidious?) enhancement of the sub-specialty with other doctors deprived of opportunities to help. This has happened with methadone for addiction subspecialty and with opioids for pain subspecialty. Regardless, law worship cannot cope with the complex art and inexact science of medicine. There are trillions of synapses; billions of neurons; thousands of overlapping pathways; hundreds of neurochemicals, and patients' chemistries differ more and change more than their faces. The law could better regulate the weather, than render always effective medical care.

2. The addiction subspecialty secured, by insouciant law, the solitary use of methadone for their addiction clinics so they were the only ones able to prescribe methadone. That they censored the fact that propoxyphene (Darvon) was at times equal in effectiveness as methadone has never been acknowledged. Propoxyphene would have reduced the need for the new addictionologists" "Methadone Clinics". The actions of addiction subspecialty founders were unethical, unprofessional, anti-Hippocratic, counter-productive, but, most importantly, still profit-making for themselves. No other medical specialty got law know-it-alls to prevent routine effective meds from being used by other physicians or disgracefully censored what else could be helpful-- Psychiatrists, cardiologists, neurologists, and so on, never sought monopolies on their meds or monarchy status for their subspecialty. I discovered this because, for years, I cared for psychiatric patients and used only propoxyphene for the few with pain symptoms. Suddenly, I realized that I had a bunch of young patients telling me "Please do not change the meds you have me on...I have my family back... my job back...and I do not have to get high with my buddies any longer. I do not want to go back to street drug use!” They all were on, for years, several psychiatric meds for their psychiatric disorders and propoxyphene for their pain. So, planning to do a study, I write the FDA being worried about "off label" prescribing, i.e., prescribing propoxyphene to prevent opioid drug abuse as described by my few patients. The FDA wrote back encouraging me with "The FDA considers off-label use to be the practice of medicine." So I researched propoxyphene and discovered that early addiction specialists debated whether to use propoxyphene or methadone for their nascent clinics- -and they chose methadone for obvious self-serving subspecialty enhancing reasons and,

\author{
Samuel A Nigro M.D \\ Retired, Assistant Clinical Professor Psychiatry, Case Western \\ Reserve University School of Medicine, USA
}

Correspondence: Dr. Samuel A Nigro M.D, Retired, Assistant Clinical Professor Psychiatry, Case Western Reserve University School of Medicine, 2517 Guilford Road, Cleveland Heights, Ohio 44I I8, USA, Tel: 216 932-0575; Email sam@docnigro.com

Received: October 15, 2015 | Published: November 24, 2015

at the same time, censored (conspired?) propoxyphene as an obvious competitor because it could not be monopolized by the addiction subspecialists as could methadone. It gets worse: About a year after I notify the FDA of my propoxyphene re-discovery, it is taken off the market, after over 50 years of overwelmingly benign usage for pain. My cynicism has today's addiction specialists protecting their methadone clinic volume again by removing propoxyphene from the market. Regardless, if any one wants to help reduce addiction, they must promote propoxyphene and its pending analogues! Not to do this is criminal now that it has been re-discovered to help addicted patients.

3. The pain subspecialty secured a semi-monopoly of pain meds by self-aggrandizing laws giving them a monitoring aegis of opioid pain meds when used by other non-pain specialty physicians-the latter not really caring and almost relieved to transfer these difficult patients to the pain docs. But then, the pain specialty CHANGES, as does all medicine about every two or so years (which is why etched-in-stone legal omniscience will never well regulate medical practice). Naturally, all medicine (and science) changes, and the pain docs developed more lucrative "injection" procedures with less and less need for pain meds. Upset, pain patients and their families complain; and thus from the White House and Congress, comes "THE DECADE OF PAIN 20002010", which promoted pain med use by instructive flyers to all physicians; many listings and info of pain meds; making pain scales to be part of "vital signs"; requiring pain evaluation efforts in nursing notes for each shift each day of every patient in all hospitals; and the releasing of methadone for general pain use by all doctors. With abortion and opening of medical records, the Oath of Hippocrates was undone, and physicians had become more and more mercenary with "pill mills" negatively impacting the addiction problem. Laws also criminalized medical care, especially physicians who unwisely succumbed to, implemented, and were seduced by the already mentioned DECADE OF PAIN promotion of pain meds. By 2006 or so, the current heroin/opioid epidemic is silently developing, with immutable laws galore being passed to solve all problems again for the inexact science 
and art of medicine, unforeseen consequences still always to undo any lasting benefits. Regardless, if any one wants to help reduce addiction, all laws regulating medical practice must be repealed; and the Hippocratic Oath must be re-established by physicians committed to "natural death" with complete closure of medical records and commitment to the rest of the Oath. (Readers relax, because lawyers and judges will do all abortions, deathwith-dignity, and euthanasia at the nearest justice center or government facility. "Unatural death" procedures can be done by almost anybody without many complications, and if you know how to have sex, doing an early abortion is easily taught in a few days at law schools along with the other metastatic LEGAL procedures like death-with-dignity and euthanasia.) Physicians must become free again to help the drug addicted who now are being treated like HIV patients were treated 30 years ago.

4. Besides freeing medicine from selfish subspecialty control, mind altering medications must be replaced by newer meds which do not offer the highs sought by addicts. Steroids, autonomic blockers, non-steroidal anti-inflammatory agents, aspirin, acetaminophen, vitamins, and analogues must be used. Rotation of these meds must be required because there is adaptation with long term use of pain meds especially. I had the opportunity of reviewing many incarcerated criminals by thousands of hours of conversation. Most laughingly said pain meds stopped working but the highs continued and discretely said that long term pain med use was a "con." In summary, almost all criminals began drugs by 12 years of age. Almost all had multiple psychiatric symptoms: anxiety, depression, attention deficit disorder, learning disabilities, mood swings, rage attacks, sleep disturbances, psychotic thinking, lack of stable identity, unnatural sex normalized, sexual abuse as victim and abuser, and an almost total lack of virtue understanding with no awareness of words of salutary behavior to replace or correct their life experiences of no childhood, no traditional family life, no virtue based fathering, no stable parenting, and no productive self-development. All were raised in a subculture teaching them adult masturbation and contemptible violence. One hundred percent said they got into drugs to ESCAPE from the overt or covert horror of their lives, again almost all beginning at age 12 or before. Regardless, if any one wants to help reduce addiction, children must have the right to a salutary childhood without adult craziness, with a safe self-developing education, and at least with knowing of the coping words derived from traditional virtues (Perhaps no child under 12 should be exposed to current television, movies and other technologically expanded press/ media programming development destroying idiocies).

\section{Acknowledgments}

None.

\section{Conflicts of Interest}

None.

\section{Funding}

None. 